\title{
Social welfare and bank performance: evidence from a stochastic neural hybrid MCDM approach
}

\begin{abstract}
Purpose- This paper investigates the endogenous relationships between banking performance and social welfare in SADC countries.

Design/Methodology/Approach- A comprehensive three-stage MCDM (Multi-Criteria Decision Making) approach based on alternative informational assumptions is applied.

Findings- Results indicate that banking performance is paradoxically associated with stagnant economic activity and higher wealth concentration for the minority. We found that SADC banking performance promotes higher HDI standards possibly via efficient financial intermediation, dissemination of best managerial practices and other forms of positive spillovers in these countries.
\end{abstract}

Orginality- This paper contributes to the MCDM literature by simultaneously exploring the key concepts of "utility functions" (using COPRAS) and "distance to ideal solutions" (using TOPSIS) in mapping and explaining the feedback and cause-effect processes between banking performance and social welfare that may exist. Another distinctive aspect is related to the computation of bias-free criteria weights, using a robust SWARA order-rank based on information entropy. Finally, this paper is concerning the endogeneity measurement, using a novel stochastic structural relationship non-linear program.

Keywords: COPRAS; Multi-criteria decision making; TOPSIS; SWARA; banking performance; social welfare 


\section{Introduction}

This paper examines the possibility of endogenous feedback between banking performance scores and social welfare indicators in the Southern African Development Community (SADC) countries. Within the financial sector, banks are seen as critical institutions of utmost importance that contribute towards economic growth. Thus, the development of a country and the welfare of its citizenry are critically dependent among other things on the soundness and efficient performance of the banking system. Efficient performance is important for several reasons. At the macro-level, banks play an intermediary function by mobilizing funds and various other financial services to retail, corporate and government sectors of the economy. Inefficient performance on their part constrains access to cheaper and affordable finance, making worthwhile investment appear unprofitable thereby slowing economic activity. Thus banks act as critical channels of investment in the provision of credit and loans to businesses. As a result, they are expected to boost demand for financial services stimulating consumption expenditure, economic growth, and it is expected, enhancing social welfare. Aluko and Ajayi (2018) state that developed banking sectors have a greater capacity to alleviate poverty and reduce financial constraints, enhance competition and promote economic growth.

In this paper, we hypothesize that gains from high banking performance either interpreted as higher productivity or efficiency translate into improved social welfare for the various participants in the economy. For instance, an efficient banking system generating banking output (volume of loans, various revenues both interest and non-interest) with fewer input resources (operational costs, deposits, personnel) potentially triggers increased uptake (access and usage) of its services generating positive economy-wide spillover effects impacting societal welfare in the process. International Monetary Fund (IMF, 2005) states that sustainable development of a 
banking system and its success in delivering support to real sector activities is largely dependent on the efficiency with which intermediation occurs.

Notwithstanding the current developments in banking research, Multi-Criteria Decision Making (MCDM) is a continuously growing research field with different approaches being continuously developed and combined to explore the underlying epistemic uncertainty in ranking alternatives and weighting criteria for measuring performance (Amin et al., 2011; Chai et al., 2013; Chang et al., 2011; Feng et al., 2011; Rajesh \& Ravi, 2015; Shaw et al., 2012; Stewart \& Durbach, 2016). Therefore, this paper contributes to the MCDM literature by simultaneously exploring the key concepts of "utility functions" (using COPRAS) and "distance to ideal solutions" (using TOPSIS) in mapping and explaining the feedback and cause-effect processes between banking performance and social welfare that may exist. Another distinctive aspect of this research is related to the computation of bias-free criteria weights, using a robust SWARA order-rank based on information entropy. While using distinct pieces of information for measuring banking performance, the maximal information entropy principle in setting SWARA weights - and, therefore, the relative importance order of each criterion for banking performance - assures that any unconsidered epistemic uncertainty will not impact performance estimates computed under the key concepts of "utility functions" and "ideal solutions". An additional contribution of this paper is concerning the endogeneity measurement, using a novel stochastic structural relationship non-linear program, built upon three major steps that encompass: (i) neural network regressions; (ii) minimization of the covariance matrix of residuals; (iii) maximization of information entropy as regards the unconditional and conditional distribution set of residuals. It is expected that empirical findings and policy implications from exploring the SADC region will contribute lessons for comparable countries in Africa and other comparable regions. 
The current study has the following structure: section reviews relevant literature, followed by section 3 presenting the stochastic-neural hybrid MCDM approach based on information entropy. The results and discussions are provided in section 4, finally, the conclusion, limitation and policy implications are given in section 5.

\section{Literature review}

Digging into the literature, we found that a repertoire of African banking studies on performance analysis focused on assessing banking efficiency using either data envelopment analysis (DEA) (Adusei, 2016; Apergis and Polemis, 2016; Wanke et al., 2019; Wanke et al., 2016; Wanke et al., 2018; Triki et al., 2017; Adesina, 2019) and/or stochastic frontier analysis ( Moyo, 2018; SarpongKumankoma et al., 2018; Osuagwu et al., 2018; Kallel et al., 2019; Ladime and Brahmana, 2021; Banyen and Biekpe, 2020; Siraj et al., 2021). The primary motivation driving the majority of these studies has been to assess the level of different types of efficiencies within which banks operate in their various contextual settings and to investigate possible causal relationships between efficiency and environmental factors that are hypothesized to influence banking performance.

Another important trend in banking research that motivated many African studies has been the need to examine structure or competition and performance. The degree of competition and efficiency with which firms operate has been shown among other things to drive the size of welfare gains that are generated in an industry. For instance, Bara et al. (2017) studying bank concentration and financial development across the SADC region pointed out that SADC banking sectors need expansion and diversification stating that concentration generates inequality and retards financial development. In Africa alone, several studies explored this aspect. For example, Apergis and Polemis (2016) found that the banking industry was characteristic of a monopolistic competition structure arguing that competitive dynamics necessary to stimulate efficiency were non-existence. 
Akande (2018) found that there is a level of competitive condition in the African banking industry between 2006-2015 and competition negatively affects efficiency, Abel and Le Roux (2016) investigate the level of competition in the Zimbabwe banking sector showing that there is a monopolistic competition. The study further showned that competition leads to efficiency improvement.

In the context of the current study, there are a few related studies that warrant special mention which focused on banking performance and some social welfare proxy indicator of the sort. For instance, In Ghana, Adeabah and Andoh (2019) investigated the welfare performance of banks with a particular focus on the role of market power and efficiency. Using a pooled ordinary least squares regression with fixed effects. They showed that apart from market power and prices, cost efficiency plays a significant role in the welfare performance of banks. Sharma et al (2013) distinguish between a bank that realizes persistence of profit as a result of efficiency and the other as a result of market power. They argue that market power-driven profits as opposed to efficiencydriven profits impose a social cost to society which erodes the social welfare of households and businesses. Maredza and Ikhide (2013a) using the DEA and the fixed effects model in a two-step procedure investigated the relationship between banking efficiency and access to banking services. They found the existence of a significant positive association between banking efficiency and access to banking services.

In another study of South Africa`s four largest banks, Maredza and Ikhide (2013b) investigated the possibility of a causal relationship between gains in banking efficiency and labour employment. Their study applied DPIN (decomposing productivity index number) a programme that uses data envelopment analysis (DEA) framework to measure and decompose total factor productivity into several measures of efficiency. Modelling banking performance using pooled 
regression they found a positive and significant association between banking efficiency and employment. However, their study did not interrogate the likely transmission of feedback channels by which changes in bank efficiency feed through to increased employment in the economy.

There are important considerations that can be drawn from the above assessment of African banking literature. Despite considerable progress realised in the African banking landscape, studies on the social welfare implications of banking performance remain scant at best. To the extent that banks are fundamentally regarded as social institutions (Booth, 2011), studying endogeneity between banking performance and their social welfare impact is a relevant issue. And yet very little is known about the social role of banking performance. Moreover, a range of studies reviewed used SFA and DEA as better methodological alternatives. None of the studies in the African context addresses the issue regarding the feedback and cause-effect processes between banking performance and social welfare that may exist, in particular, the application of MCDM models which is addressed in this current study. Wanke et al. (2017) argue that a more systematic research approach to banks is still lacking in African countries.

\section{Stochastic-neural hybrid MCDM approach based on information entropy}

This systematic review on using MCDM methods for measuring banking performance revealed not only a heterogeneous scenario, where it is not possible to claim whether a specific method is preferable to the detriment of the others, but also a myriad of alternative methodological approaches where a creative effort is made to deal with epistemic uncertainty at different levels of analysis by the combination of distinct methods. However, very often the reasons, strengths, and weakness of each method used in hybrid MCDM combinations for handling epistemic uncertainty are not properly discussed. These issues are addressed next. 
As regards weight definition, SWARA, differently from other MCDM methods, is particularly useful as long as it computes the preferences or relative importance for each criterion as a relative efficiency score anchored in the most important criterion (Zolfani et al., 2018 . Hence, SWARA helps in assigning efficiency levels for each criterion, either within the ambit of partial utility functions derived in COPRAS or within the ambit of distance to ideal solutions computed in TOPSIS. Analogously to COPRAS, SWARA criteria weighting also has its grounds on the wellknown economic efficiency concept, which aims at measuring relative distances between two units of analysis. Yet, it is also worth noting the resemblance with TOPSIS, where one of these units of analysis consists of the ideal solutions, which could the maximal achievable value in case of positive criteria or the minimal achievable value in case of negative criteria .

The maximal entropy principle states that the probability distribution that best represents the current state of knowledge given prior data is the one with the largest entropy. Putting into other words, this principle limits the decision-maker's choice from all the possible different probability distributions that might express the current state of knowledge. It is the cornerstone of information theory, providing a constructive criterion for setting up probability distributions based on partial knowledge while enabling a type of statistical inference which is called the maximum entropy estimate. This will be the system with the largest remaining uncertainty - i.e. heterogeneity or dispersion - where no extra biases or uncalled assumptions can enter into the analysis (Teixeira et al., 2019). Therefore, by determining criteria weights in SWARA based on their information entropy rank-order, this research assures that these are bias-free inputs to enter COPRAS and TOPSIS computations. This means that the distributional profiles of COPRAS and TOPSIS performance scores contain the maximal possible 
heterogeneity or dispersion level, working as a robust or worst-case scenario against eventual unconsidered assumptions in this research.

In turn, COPRAS, differently from other MCDM methods, helps in establishing a partial utility function for each banking performance criteria (Mahdiraji et al., 2018. Readers should recall that utility functions are a well-known economic concept frequently applied in MCDM methods (Diaz-Balteiro et al., 2017). Precisely, utility functions measure the performance of a set of alternatives given certain criteria weights (Kassem \& Jafar Hakim, 2016; Rezaeisaray et al., 2016). The underlying modelling of utility functions in COPRAS is one of the most simple and can be easily understood by decision-makers since it does not require additional specific constraints on the preference structure besides the aggregation formula. Hence, the relationships between each criterion and their partial utility functions can be established in a straightforward fashion (Gandhi et al.,2016). Besides, the simplicity of additive aggregation makes the utility function approach particularly appealing. Only relatively minor assumptions are needed and these are primarily related to weight definition, often regarded as scaling factors (Almeida et al., 2016).

On the other hand, TOPSIS, following Aye et al. (2018) and Andrade et al. (2020), develops cardinal or scale metrics on positive and negative ideal solutions that are obtained through linear combinations of the original criteria. Putting into simpler wording, these combinations are formed by the best-achieved values for the positive criteria and the worst achieved values for negative criteria, in a way that best and worst (i.e. positive and negative ideal, respectively) limits for possible achievable performance are determined. TOPSIS measures performance in qualitative terms, using cardinal distances (scores) from ideal solutions while simultaneously presents an ordinal ranking of them. These authors also state that TOPSIS amongst the plethora of existing MCDM models is the one with a high resemblance with consecrated non- 
parametric and parametric efficiency measurement methods, such as Data Envelopment Analysis and Stochastic Frontier Analysis, respectively.

\subsection{Stage 1: SWARA}

SWARA is a general tool that is used for calculating criteria weights within the ambit of performance measurement, as well as the respective resulting importance levels (Zolfani et al., 2018). It is one of the few existing MCDMs that are based on a rational dispute resolution method (Mardani et al., 2019). Analogously to other MCDMs, however, experts also present critical roles in terms of decision-making inputs. First, the preferences of experts are obtained. Then the average expert's judgements are computed. Subsequently, the comparative importance of each criterion is calculated. Next, results are sorted in descending order. Finally, the weight of a given criterion is calculated based upon the relative importance of the next most important criterion (Stanujkic et al., 2015). In this research, the preferences of experts were replaced by the information entropy values computed by each criterion. The idea was to observe the principle of maximal entropy, which assures bias-free decision in the case there are no available estimators for the prior distributions of each criterion. The SWARA method is described next.

Step 1: Sort criteria from the highest to the lowest importance.

Step 2: First of all, the preference of the first criterion is null. Allocate decision-maker preferences to the second most important criterion; repeat this until the last importance criterion is reached. These preferences are based on comparing this specific criterion with the first criterion. Compute their pairwise relative importance denoted by $S_{j}$, which shows the ratio of this comparison.

Step 3: Set-up pairwise efficiency criteria $K_{j}$ by:

$K_{j}=\left\{\begin{array}{l}1, j=1 \\ S_{j}+1, j>1\end{array}\right.$ 
Step 4: Compute relative weights $\left(q_{j}\right)$ based on sorted pairwise efficiency concerning the importance criterion rank:

$q_{j}=\left\{\begin{array}{cc}1 & j=1 \\ \frac{K_{j-1}}{K_{j}} & j>1\end{array}\right.$

Step 5: Compute final weights as $E_{j}=\frac{q_{j}}{\sum_{k=1}^{n} q_{k}}$, where $E_{j}$ denotes the weight of each criterion $j$.

\subsection{Stage 2: COPRAS and TOPSIS}

\section{COPRAS}

COPRAS was first introduced more than two decades ago by Zavadskas and Kaklauskas (1996).

Since then, several different types of research have been published on possible alternative ways for combining SWARA and COPRAS e.g. Nakhaei et al., 2016; Valipour et al., 2017); SWARA and Fuzzy COPRAS (Bekar et al., 2016; Mishra et al., 2020); and COPRAS and other MCDMs (Dhiman and Deb, 2020; Büyüközkan and Göçer, 2019; ). The next lines briefly present the major steps of the COPRAS method:

Step 1: Create a decision-making matrix $X$, containing $m$ criteria and $n$ alternatives:

$X=\left(\begin{array}{ccc}a_{11} & \ldots & a_{1 n} \\ \vdots & \ddots & \vdots \\ a_{m 1} & \cdots & a_{m n}\end{array}\right) i=1,2, \ldots n ; j=1,2, \ldots, m$

Step 2: Normalize the decision matrix $X$ by computing:

$\overline{x_{i j}}=\frac{x_{i j}}{\sum_{j=1}^{n} x_{i j}}$

Then the decision matrix will be:

$\bar{X}=\left(\begin{array}{ccc}\bar{x}_{11} & \cdots & \bar{x}_{1 n} \\ \vdots & \ddots & \vdots \\ \bar{x}_{m 1} & \cdots & \bar{x}_{m n}\end{array}\right)$

Step 3: Compute the weighted normalized decision matrix by means of: 
$\widehat{x_{l j}}=\bar{x}_{i j} \times E_{j} ; i=1,2, \ldots, n ; j=1,2, \ldots, m$

Therefore,

$\widehat{X}=\left(\begin{array}{ccc}\hat{x}_{11} & \ldots & \hat{x}_{1 n} \\ \vdots & \ddots & \vdots \\ \hat{x}_{m 1} & \cdots & \hat{x}_{m n}\end{array}\right) ; i=1,2, \ldots, n ; j=1,2, \ldots, m$

Step 4: Sum-up the larger values that are more preferable, named as $P_{i}$ :

$$
P_{i}=\sum_{j=1}^{k} \overline{x_{i j}}
$$

Step 5: Sum-up the smaller values that are more preferable, named as $R_{i}$ :

$$
\boldsymbol{R}_{i}=\sum_{j=k+1}^{k} \overline{x_{i j}}
$$

Then the number of criteria that should be minimized is given by the difference $\mathrm{m}-\mathrm{k}$.

Step 6: Minimize $\boldsymbol{R}_{i}$ observing eq. (8):

$$
R_{\text {min }}=\min _{i} R_{i} ; i=1,2, \ldots, n
$$

Step 7: Compute the relative significance of each alternative $Q_{i}$ as given:

$$
Q_{i}=P_{i}+\frac{R_{\min } \sum_{i=1}^{n} R_{i}}{R_{i} \sum_{i=1}^{n} \frac{R_{\min }}{R_{i}}}
$$

Step 8: Identify the optimal alternative i, given by K, as is illustrated:

$$
K=\max _{i} Q_{i} ; i=1,2, \ldots, n
$$

Step 9: Prioritize alternatives in a descending order.

Step 10: Determine the utility degree $N$ of each subsequent alternative $i$, given as:

$$
N_{i}=\frac{Q_{i}}{Q_{\max }}
$$




\section{TOPSIS}

TOPSIS departs from a matrix formed of $m$ alternatives and $n$ financial indicators, with the intersection of each unit and financial indicator given as $x_{i j}$ (Barros and Wanke, 2015). Hence, one gets a matrix $\left(x_{i j}\right)_{m x n}, \mathrm{k}=1,2,3$. This matrix $\left(x_{i j}\right)_{m x n}$ should be firstly normalized from a regulated matrix $R^{*}=\left(r_{i j}\right)$ through the square root of the sum of the scores.

$r_{i j}=\left(x_{i j}\right) / \sqrt{\sum_{i=1}^{m} x_{i j}^{2}}, i=1 \ldots m$ and $j=1 \ldots n$

After normalization, the weighted normalized decision matrix should be calculated, observing Eq. (14), by multiplying the normalized SWARA weights by the normalized criteria matrix obtained through the financial indicator-unit data matrix by Eq (15).

$W=\left(E_{j} r_{i j}\right)_{m \times n}$

where $E_{j}$ is the SWARA weight attributed to each financial indicator $j$ and $\sum_{j=1}^{n} E_{j}=1$.

Considering the weighting criteria, the non-ideal solution $\left(A_{\text {neg }}\right)$ and the ideal solution $\left(A_{\text {pos }}\right)$ are defined observing Eqs. (16) and (17):

$$
A_{n e g}=\left\{\left\langle\min \left(E_{j} r_{i j} \mid i=1 \ldots m\right) \mid j \in J_{+}\right\rangle,\left\langle\max \left(E_{j} r_{i j} \mid i=1 \ldots m\right) \mid j \in J_{-}\right\rangle\right\}=\left\{\alpha_{n e g j} \mid j=1 \ldots n\right\}
$$

$$
A_{\text {pos }}=\left\{\left\langle\max \left(E_{j} r_{i j}|i=1 \ldots m| j \in J_{+}\right\rangle,\left\langle\min \left(E_{j} r_{i j}|i=1 \ldots m| j \in J_{-}\right\rangle\right\}=\left\{\alpha_{\text {pos } j} \mid j=1 \ldots n\right\}\right.\right.
$$

The ideal solution is composed of all best scores for each financial indicator, while the nonideal solution is formed by the worst scores attained for the very same indicator. In Eqs (16) and (17), $J_{+}$and $J_{-}$represent, respectively, the set of indicators that should be maximized for better banking performance and those that should be minimized for the sake of the same objective. 
Given the best and the worst alternatives, the distance $\mathrm{D}_{\text {neg }}$ between a given unit $i$ and the negative-ideal solution $A_{\text {neg }}$ is calculated using Eq. (18):

$\left.D_{n e g i}=\sqrt{\sum_{j=1}^{n}\left(E_{j} r_{i j}\right.}-\alpha_{n e g j}\right)^{2}, i=1 \ldots m$

and the distance $D_{\text {ipos }}$ between a given dyad $i$ and the positive-ideal solution $A_{\text {pos }}$ is computed by observing Eq. (19).

$\left.D_{\text {posi }}=\sqrt{\sum_{j=1}^{n}\left(E_{j} r_{i j}\right.}-\alpha_{p o s j}\right)^{2}, i=1 . . m$

where $D_{n e g} i$ and $D_{\text {pos } i}$ are the distances measured in the Euclidean space considered from a given unit $i$ to the negative- and posited-ideal solutions yielded by the $j$ financial criteria.

\subsection{Stage 3: Stochastic Structural Relationship Program based on Neural Regressions}

Step 1: Residual computation based on neural regressions

This paper proposes a novel structural relationship model based on neural network regressions to unveil the eventual endogenous relationships among performance scores and social welfare variables in SADC countries, in terms of the residuals produced by the following models.

- Model 1: TOPSIS f(COPRAS, GDP pc, Gini, HDI, Inflation)

- Model 2: COPRAS f(TOPSIS, GDP pc, Gini, HDI, Inflation)

- Model 3: GDP pc f(COPRAS, TOPSIS, Gini, HDI, Inflation)

- Model 4: Gini $\quad \sim$ f(COPRAS, TOPSIS, GDP pc, HDI, Inflation)

- Model 5: HDI $\quad \sim$ f(COPRAS, TOPSIS, GDP pc, Gini, Inflation)

- Model 6: Inflation f(COPRAS, TOPSIS, GDP pc, Gini, HDI) 
These residuals are subsequently used to generate a full set of conditional residual distributions between the respective dependent variable pairs identified in each model. These conditional residual distributions allow exploring the directional relationships that may exist among variables. Results for the optimal neural network architecture are given in the Appendix. Step 2: Optimal residual weights for the minimal covariance matrix

The relative importance of models (1)-(6) in explaining the feedback process between banking performance and social welfare in SADC countries, besides the endogenous nature of these variables, were explored, respectively, by the variances of each model and the covariances between models. Variances and covariances of the residuals $\left(R_{i}\right)$ of these six models are simultaneously minimized by a non-linear stochastic optimization problem, as presented in Model (20). $w_{i}$ stands for the weights - which range from 0 to 1 - assigned, respectively, to the residual vectors of each one of the six models previously described. The values of $w$ are optimized so that the variance (Var) and covariance (Covar) of the pooled residuals are minimal. Model (20) was solved through differential evolution (DE). DE is a research stream of genetic algorithms, also emulating natural selection and evolution. Readers should refer to Ardia et al. (2011) and Mullen et al. (2011) for further details.

$\min \left[\operatorname{Var}\left(\sum_{i=1}^{6} w_{i} * R_{i}\right)+\left(2 * \sum_{i, j=1}^{6} \operatorname{Covar}\left(w_{i} * w_{j} * R_{i} * R_{j}\right), i \neq j, j<i\right)\right]$

subject to

$\sum_{i=1}^{6} w_{i}=1$

$0 \leq w_{i} \leq 1 \quad \forall i$ 
Residuals of the MLP models were bootstrapped 100 times allowing the collection of a distributional profile of $w$ for the most accurate prediction of efficiency scores and contextual variables.

Step 3: Cause-Effect and Feedback mapping based on maximal information entropy principle

The principle of maximum entropy states that the probability distribution which best represents the current state of knowledge is the one with largest entropy, in the context of precisely testable information. In this third step, a full combinatorial set of conditional distributions of residuals $\left(\mathrm{CR}_{\mathrm{k}}\right)$ was computed. The previous 100 bootstrapped replications for the unconditional individual residuals $\left(\mathrm{R}_{\mathrm{i}}\right)$ of each model served as cornerstones for this computation, where $\mathrm{CR}_{\mathrm{k}} \sim \mathrm{f}\left(\mathrm{R}_{\mathrm{i}} / \mathrm{R}_{\mathrm{j}}\right)$ for all $\mathrm{i}$ and $\mathrm{j}, \mathrm{i} \neq \mathrm{j}$, and $\mathrm{K}=\mathrm{i} * \mathrm{j}-\mathrm{i}=6 * 6-6=30$. Similarly, DE was employed for solving the following non-linear integer programing model to diagnose whether conditional distributions of for each pair of residuals presented significant differences in terms of directions. For instance, weights assigned to $f\left(R_{i} / R_{j}\right)$ could yield higher entropy than those assigned to $f\left(R_{j} / R_{i}\right)$ levels in comparison to the unconditional residuals analyzed in Step 2 to unveil endogeneity. This non-linear integer programming problem is depicted in model (21).

$\max \left[\left(\sum_{i} \sum_{j} H\left(f\left(R_{i} / R_{j}\right) * w_{i} * w_{j}\right)\right) O R\left(\sum_{i} \sum_{j} H\left(g\left(R_{i}, R_{j}\right) * w_{i} * w_{j}\right)\right), i \neq j\right]$

subject to

$\sum_{i=1}^{6} w_{i}=1$

$0 \leq w_{i} \leq 1, \quad \forall i$

Where: 
$H($.$) denotes the information entropy function,$

$g\left(R_{i}, R_{j}\right)$ denotes the unconditional marginals of the residuals from models (1) - (6), $\forall i, j$, $i \neq j$,

$f\left(R_{i} / R_{j}\right)$ denotes the conditional distribution of the residuals from models (1) - (6), $\forall i, j, i \neq j$.

This non-linear integer programming model returns the structural relationship among dependent variables defined in models (1)-(6) for which information entropy is maximal. This assures the uniqueness and consistency of the probabilistic weight profile computed in Step 2 for which the overall residual variance is also minimal. Hence, weights computed in Step 2 were used as starting values for Step 3 optimization. Again, differential evolution was employed for finding optimal solutions as regards maximal entropy for each $i j$ pair. This model returns, for a given $i j$ pair, whether its relationship is endogenous or whether $i$ causes $j$ (or the other way around). Table 1 presents the pseudo code used for computing $f($.$) and g($.$) estimates used in the Step 3$ optimization model.

Table 1. Pseudo code used for computing $f($.$) and g($.$) estimates used in Step 3$.

\begin{tabular}{|r|l|}
\hline 1 & Fit the statistical distributions for each model residuals \\
\hline 2 & Calculate the correlation matrix between all model residuals \\
\hline 3 & Fit the best distribution of residuals for each model (cf. Table 2) \\
\hline 4 & Generate multivariate Copulas preserving the correlation and distribution \\
\hline 5 & structure for all model residuals \\
\hline a & for p in percentiles do \\
\hline b & for i in 1 to models do \\
\hline
\end{tabular}




\begin{tabular}{|r|l|}
\hline $\mathrm{c}$ & for $\mathrm{j}$ in i to models do \\
\hline $\mathrm{d}$ & Evaluate the conditional distribution of copula ij \\
\hline $\mathrm{e}$ & Evaluate the unconditional marginal distributions of copula ij \\
\hline $\mathrm{f}$ & Solve model (21) using Differential Evolution Approach \\
\hline
\end{tabular}

Table 2. Distributional fit for residuals obtained in models (1)-(6).

\begin{tabular}{|cccc|}
\hline Model & Distribution & \multicolumn{2}{c|}{ Parameters } \\
\hline TOPSIS & Log normal & meanlog & sdlog \\
& & -1.11 & 0.07 \\
COPRAS & Gamma & shape & rate \\
& & 118.04 & 162.06 \\
GDP pc & Logistic & location & scale \\
& & -0.0045 & 0.0401 \\
HDI & Logistic & location & scale \\
& & -0.0012 & 0.0104 \\
& & shape & rate \\
Inflation & Gamma & 11.31 & 41.40 \\
& & location & scale \\
Gini & Logistic & -0.0001 & 0.0131 \\
& & & \\
\hline
\end{tabular}

In summary, this section mainly focused on detailed description on three MCDM methods, namely, SWARA, COPRAS and TOPSIS, in addition, we clearly illustrate each of these three methods by making relevant comparisons, the description and discussion of these provided the basis for presenting the results regarding bank performance, while the last part of this section 
focused on the description and discussion of the stochastic neural regression method, through which the endogenous relationship between social welfare and bank performance can be addressed. As we can see, among the six models established, three different types of distributions are presented including log normal distribution, Gamma distribution and logistic distribution.

\section{Results and discussions}

Excluding the newest member state, Comoros which joined in 2017, the countries selected for analysis account for $80 \%$ of countries in the SADC economic bloc. Twelve countries sampled for analysis include Angola (6), Botswana (5), Lesotho (3), Madagascar (3), Malawi (4), Mauritius (7), Mozambique (3), Namibia (4), South Africa (12), Eswatini (4), Tanzania (6), and Zambia (6). The number in parentheses represents the number of banks sampled in each country which aggregate to 63 . Our analysis span over 11 years covering the period $2005-2015$. Banking data for DRC and Seychelles was missing and to preserve uniformity and maintain consistency in data sources and collection, we removed the two countries from our sample. In the case of Zimbabwe, the data set was insufficient because the financial statements reported by Bankscope only starts from 2009.

Cooper et al. (2007) state that the rule of thumb regarding the sufficiency of observations is that the number of DMUs should at least be three times greater than the total of the number of inputs and outputs used in the analysis i.e. the number of DMUs $=3 \times($ number of inputs + number of outputs). In the present context, 3 times ( 3 inputs +3 outputs) simplifies to 18 which defines the minimum required number of DMUs suitable for this study. The number of DMUs under consideration is 63 which is greater than that proposed by Cooper et al. (2007) by a factor of 3.5 . All the data variables used in this paper were obtained from the Bankscope database and all monetary values are expressed in the currency of the country concerned. The sample in this study 
is fairly representative of banking in the SADC bloc, given that the number of banks under consideration represents at least $75 \%$ of total banking assets and liabilities in each country. Ultimately, we explore 693 observations ( 63 banks $\times 11$ periods) of SADC banking data. The choice of selected countries and the number of banks sampled in each country for examination was informed by the need to ensure a full data set availability for the entire period of the study.

\section{Measurement issues and data variables}

On reviewing literature regarding measurement issues, there is however controversy on whether customer deposits are more suitably treated as inputs or outputs. The choice selected has implications on performance measurement. Two approaches are predominantly followed in most efficiency studies on banking performance, the intermediation /asset approach and the production approach. Less prominent options include the value-added and the user-cost approach. Under the intermediation approach, a bank deposit is regarded as an input whereas under the production approach it is treated as an output. In keeping with empirical literature and modern-day banking, the intermediation approach is chosen for this study. Renowned researchers like Elyasiani and Mehdian (1990) and Berger and Humphrey (1997) are in favour of the intermediation approach. They maintain the view that the intermediation approach is more inclusive of interest expenses, which generally account for more than half of total banking expenses. The other argument by Elyasiani and Mehdian (1990, p. 543) is that banks "buy rather than sell deposits" and for that reason argue that deposits are more appropriately classified as inputs rather than outputs.

Table 3 summarises and describes bank-level variables that are used in the first stage to estimate efficiency. All variables have been chosen carefully to mirror salient aspects of modernday banking as reflected in empirical literature as well as in the SADC banking industry and elsewhere in the world. 
Table 3: Description of banking input and output variables

\begin{tabular}{|l|l|l|}
\hline \multicolumn{2}{|l|}{ Variable } & Definition/Description \\
\hline Inputs & Customer deposits & Total current, savings and fixed term. \\
\hline & Fixed assets & Total long-term tangible assets used in the operation of a bank. \\
\hline Output & Gross Loans & Consumer/retail, corporate, commercial and other loans. \\
\hline & Net interest income & (Interest income on loans + other interest income) - (interest \\
& & expense on customer deposits + other interest expenses) \\
\hline & Non-interest income & Fee income, commission income and other \\
\hline
\end{tabular}

In order to examine the possibility of endogenous feedback between banking performance

scores and social welfare indicators, socio-demographic contextual variables are also introduced into the analysis. Social welfare proxy indicator variables employed in this study include per capita GDP (Islam and Clark, 2002), human development index (HDI) (van den Bergh and Botzen, 2018); Gini index (Wodon and Yitzhaki, 2002) and inflation (Lagos and Rocheteau, 2005).

Table 4 reports on the descriptive statistics of the data used in this analysis.

\begin{tabular}{|c|c|c|c|c|c|c|c|c|}
\hline \multicolumn{3}{|c|}{ Criteria } & \multirow[b]{2}{*}{ Max } & \multirow[b]{2}{*}{ Mean } & \multirow[b]{2}{*}{ SD } & \multirow[b]{2}{*}{$\mathrm{CV}$} & \multirow[b]{2}{*}{ Skewness } & \multirow[b]{2}{*}{ Kurtosis } \\
\hline Variable & sign & Min & & & & & & \\
\hline Loan & + & 12.00 & 3638280.00 & 133547.22 & 320688.32 & 2.40 & 6.03 & 50.39 \\
\hline \multicolumn{9}{|l|}{ net } \\
\hline \multicolumn{9}{|l|}{ interest } \\
\hline inc & + & 0.00 & 645473.00 & 16009.92 & 54186.53 & 3.38 & 8.06 & 76.69 \\
\hline
\end{tabular}




\begin{tabular}{|c|c|c|c|c|c|c|c|c|}
\hline \multicolumn{9}{|l|}{ Non- } \\
\hline interest & & - & & & & & & \\
\hline inc & + & 7872.00 & 429700.00 & 11942.18 & 33135.36 & 2.77 & 6.61 & 57.80 \\
\hline \multicolumn{9}{|l|}{ Fixed } \\
\hline assets & - & 0.10 & 303411.00 & 8906.57 & 30713.26 & 3.45 & 6.50 & 46.68 \\
\hline Deposits & - & 0.00 & 6033084.00 & 211647.30 & 521054.15 & 2.46 & 6.37 & 55.38 \\
\hline \multicolumn{9}{|l|}{ Non- } \\
\hline \multicolumn{9}{|l|}{ interest } \\
\hline expenses & - & 0.00 & 784879.00 & 15684.13 & 56510.97 & 3.60 & 8.66 & 89.13 \\
\hline GDPPC & & 376.89 & 9476.67 & 4105.81 & 2967.52 & 0.72 & 0.07 & -1.58 \\
\hline HDI & & 0.35 & 0.79 & 0.57 & 0.11 & 0.19 & 0.21 & -0.96 \\
\hline Inflation & & -60.50 & 27.28 & 7.10 & 8.17 & 1.15 & -4.93 & 39.43 \\
\hline GINI & & 35.23 & 65.30 & 50.76 & 9.76 & 0.19 & -0.02 & -1.49 \\
\hline
\end{tabular}

As for SWARA weights, readers should recall that the maximal information entropy principle was observed. One can note in Fig. 1. (left), the higher the dispersion of given criteria, the higher its information entropy and the resemblance to a uniform distribution. 


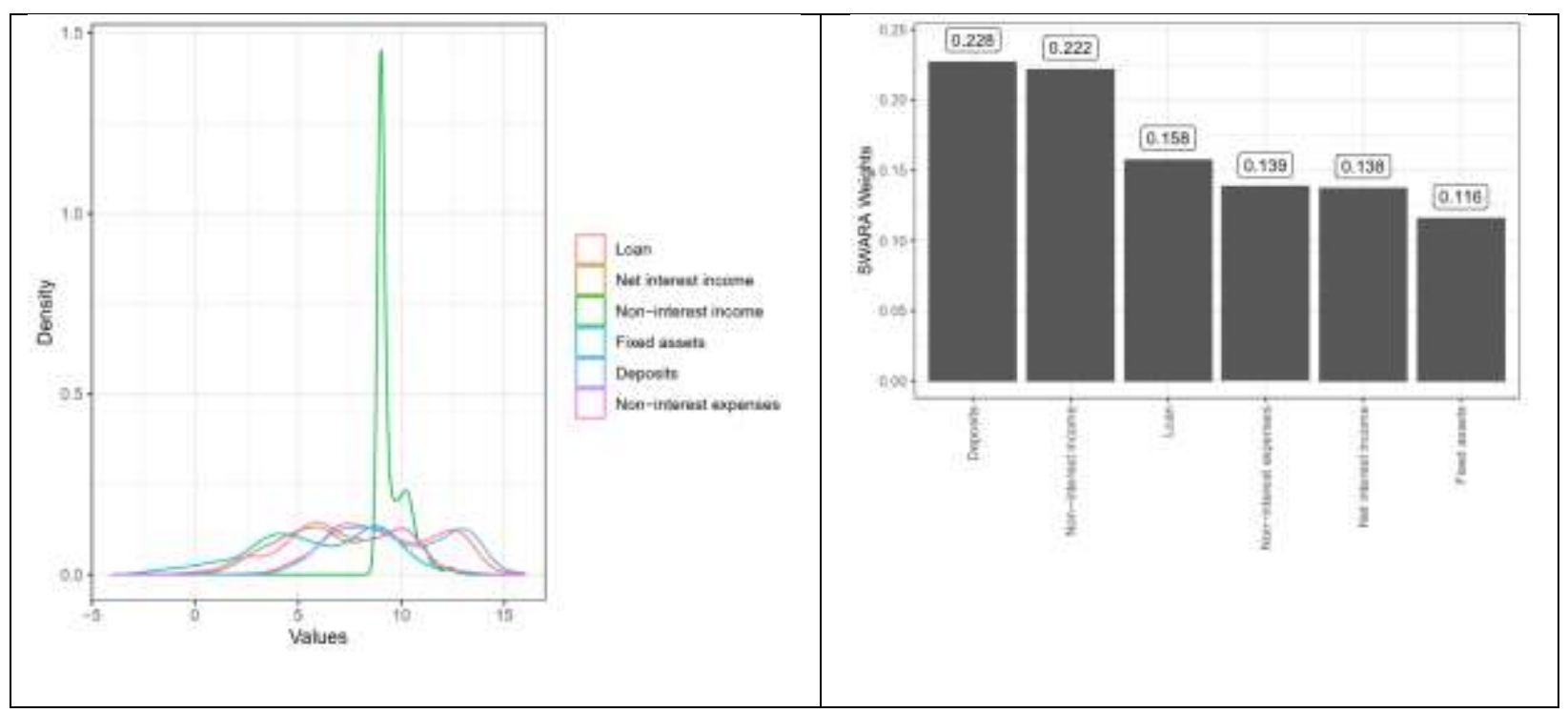

Fig. 1. Information entropy mass distribution (left) and SWARA weights (right).

Results for the density plots of COPRAS and TOPSIS scores are given in Fig. 2, where it is interesting to note that both sets present good discrimination from one another. It is also noteworthy that performance scores are higher under the "distance to ideal solutions" assumption than under the "utility function" assumption. This might suggest that higher criteria slacks could be somehow useful, from a managerial perspective, to achieve higher financial performance. The correlogram presented in Fig. 3 indicates a positive moderate association between TOPSIS and COPRAS scores. Besides, Fig. 3 also reveals an intricate network of associations among banking performance scores and social welfare variables in SADC countries. The nature of these associations - whether cause-effect (directional) or endogenous (feedback) - can be unveiled by the conditional and unconditional information entropies of the residuals, which are reported, respectively, in Tables 5 and 6 for percentile 0.975 and serve as inputs for model (21).

Table 5. Information Entropy of conditional distribution of [ROW] given that [COLUMN] for percentile 0.975 .

\begin{tabular}{|l|l|l|l|l|l|l|}
\hline Models & TOPSIS & COPRAS & GDP Per Capita & HDI & Inflation & GINI \\
\hline
\end{tabular}




\begin{tabular}{|l|l|l|l|l|l|l|} 
TOPSIS & & 0.57628 & 0.575845 & 0.576356 & 0.575834 & 0.577783 \\
\hline COPRAS & 0.571813 & & 0.577415 & 0.575637 & 0.57555 & 0.57734 \\
\hline GDP Per Capita & 0.57154 & 0.561006 & & 0.574764 & 0.574562 & 0.573722 \\
\hline HDI & 0.572355 & 0.561587 & 0.571923 & & 0.573415 & 0.571446 \\
\hline Inflation & 0.566731 & 0.57171 & 0.562702 & 0.556998 & & 0.576163 \\
\hline GINI & 0.573278 & 0.568536 & 0.574411 & 0.572129 & 0.573456 & \\
\hline
\end{tabular}

Table 6. Information Entropy of unconditional distributions for percentile 0.975. (*)

\begin{tabular}{|l|l|l|l|l|l|l|}
\hline Models & TOPSIS & COPRAS & GDP Per Capita & HDI & Inflation & GINI \\
\hline TOPSIS & & 0.427983 & 0.352937 & 0.29534 & 0.394197 & 0.368436 \\
\hline COPRAS & 0.427983 & & 0.314601 & 0.36885 & 0.301144 & 0.377826 \\
\hline GDP Per Capita & 0.352937 & 0.314601 & & 0.366734 & 0.345086 & 0.288112 \\
\hline HDI & 0.29534 & 0.36885 & 0.366734 & & 0.391367 & 0.347962 \\
\hline Inflation & 0.394197 & 0.301144 & 0.345086 & 0.391367 & & 0.334979 \\
\hline GINI & 0.368436 & 0.377826 & 0.288112 & 0.347962 & 0.334979 & \\
\hline
\end{tabular}

(*) Differently for the conditional distribution matrix, the unconditional distribution is a symmetric one. 


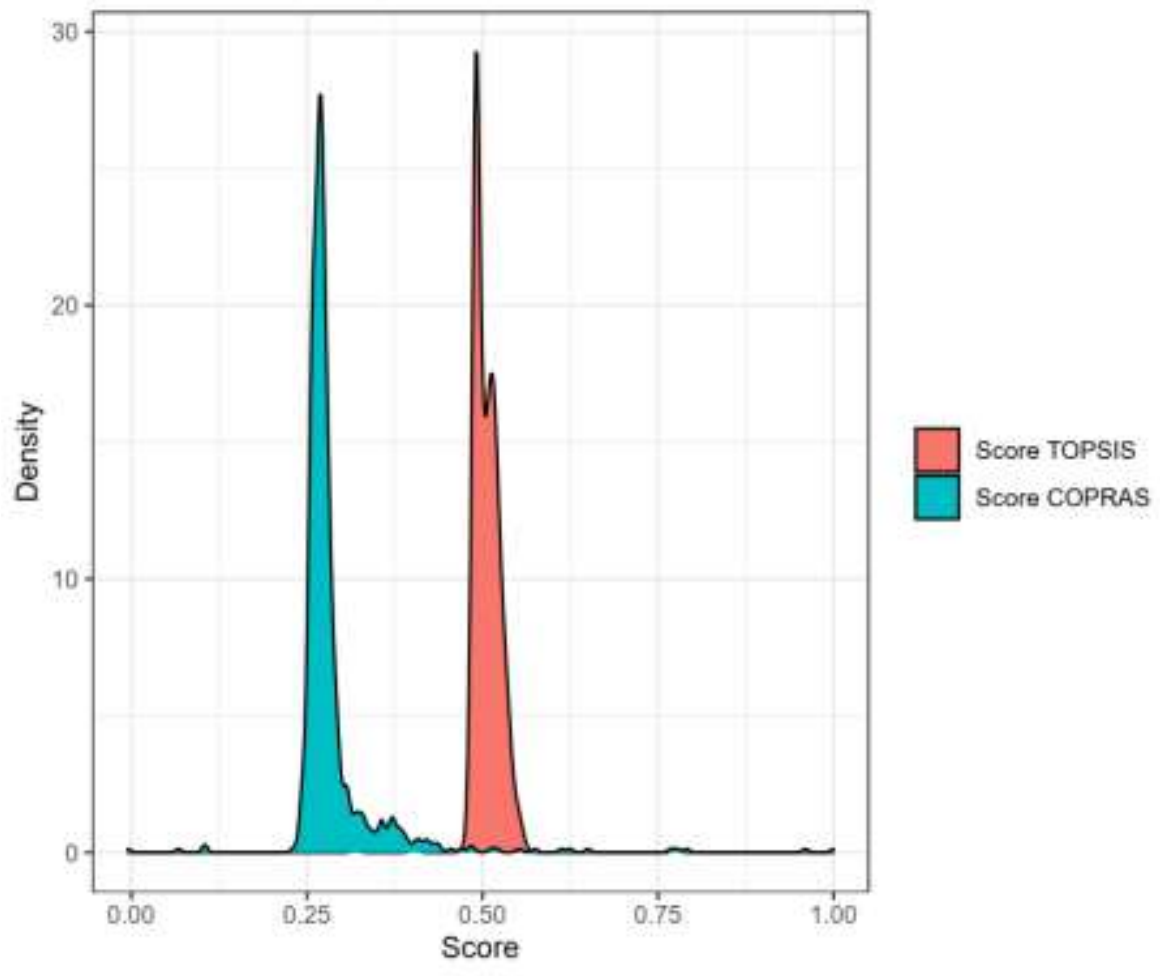

Fig. 2. Density plots for COPRAS and TOPSIS scores. 


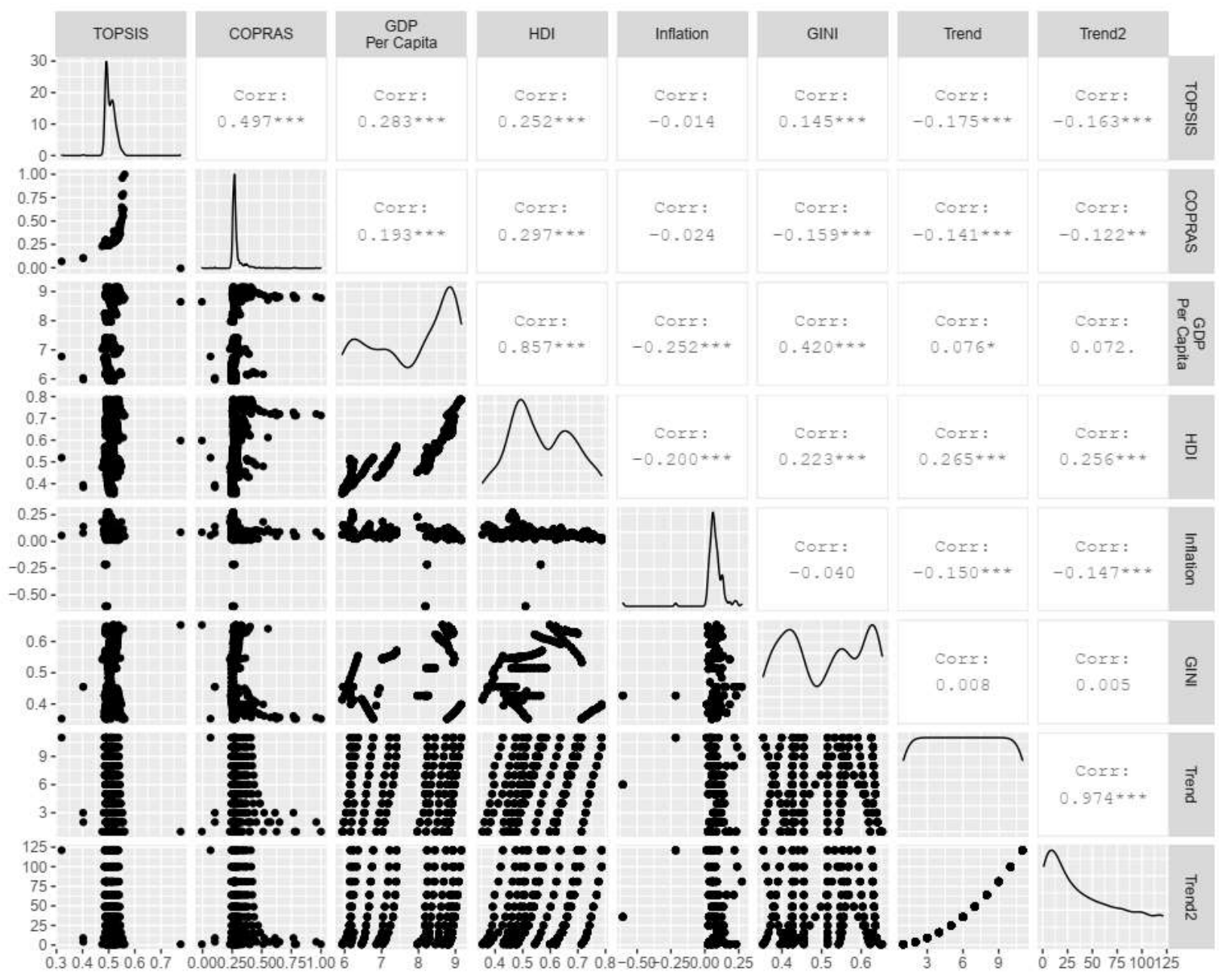

Fig. 3. Correlogram among performance scores and financial criteria.

Results presented in Fig. 4 and Fig. 5 also serve as inputs for model (21) and consist of model (20) results concerning the relative importance of each variable in achieving minimal residual covariance. It is worth noting that Gini and HDI social-welfare variables and TOPSIS scores present a prominent role in explaining joint residual variation. On the other hand, COPRAS, inflation, and GDP pc play a coadjunct role, which may shed some light on the very nature of cause-effect relationships. Banking performance scores, either measured by TOPSIS or COPRAS - although ideal solution slacks impact on utility functions-, are powerful drivers for understanding social-welfare issues in SADC countries (cf. Fig. 6). On the negative side, banking 
performance is associated with higher wealth concentration altogether stagnant economic activity (higher Gini, higher inflation rates, and lower GDP pc). Paradoxically, however, banking performance appears to promote higher HDI standards, possibly due to the dissemination of best managerial practices and other forms of positive spillovers in these African countries. Higher HDI standards is often a reflex of higher levels of human and physical capital, which in turn, helps in promoting fair development with controlled inflation rates. Lower inflation rates, on the other hand, help in improving Gini and by extension, indirectly, promoting higher levels of GDP pc. Therefore, it is possible to affirm that the path for economic development in SADC countries, from the banking perspective, depends first of all on human and physical capital spillovers that improve the match between demand and supply for several goods in these African societies, progressively raising the GDP pc levels. However, in the absence of such spillovers, the banking role in SADC countries may be found completely detached from social welfare, boosting wealth concentration in the hands of a few.

In summary, these results generate important and interesting implications as below: it seems that deterioration of bank performance would be helpful to reduce the price level, increase the personal wealth as well as improve the equal distribution of income among different groups of people, as reflected by its positive impacts on Gini index, inflation and negative impact on GDP per capita, however, it will reduce the life expectancy, decrease the education level as well as lower the gross national income per captail, as reflected by its positive impact on Human development index. More importantly, if we look at the relationship more carefully, we can notice that Gini index has a positive influence on human development index, while the negative impact is found for GDP per capita. We also observe that higher level of human development index is helpful to reduce the price level, as reflected by its negative impact on inflation. Considering all these aspects 
together, we would argue that rather than a deterioration of bank performance, there should be an emphasis on the improvement of bank performance, the results of which would be a direct positive impact on human development index, which will also be indirectly improved by an increase in Gini index and a decrease in the level of GDP per capita. Although there would be an increase in the level of inflation derived from the improvement in bank performance, the increase in the price level would be alleviated by the improvement in human development index. Therefore, the banking sector in SADC countries should focus on findings ways to reduce the expenses and expanding the volumes of loans and other sources of income.

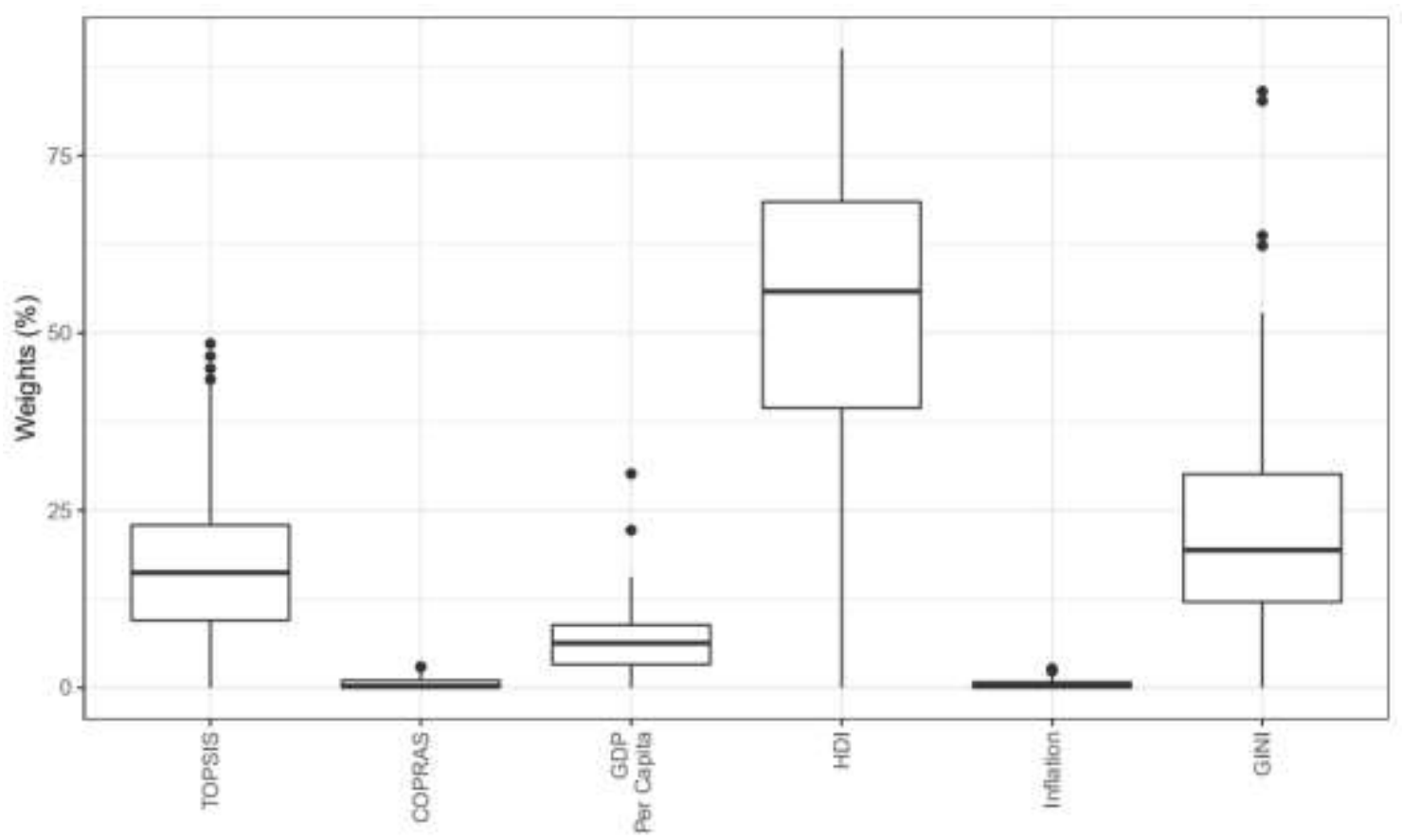

Fig. 4. Relative importance of models (1)-(6). 


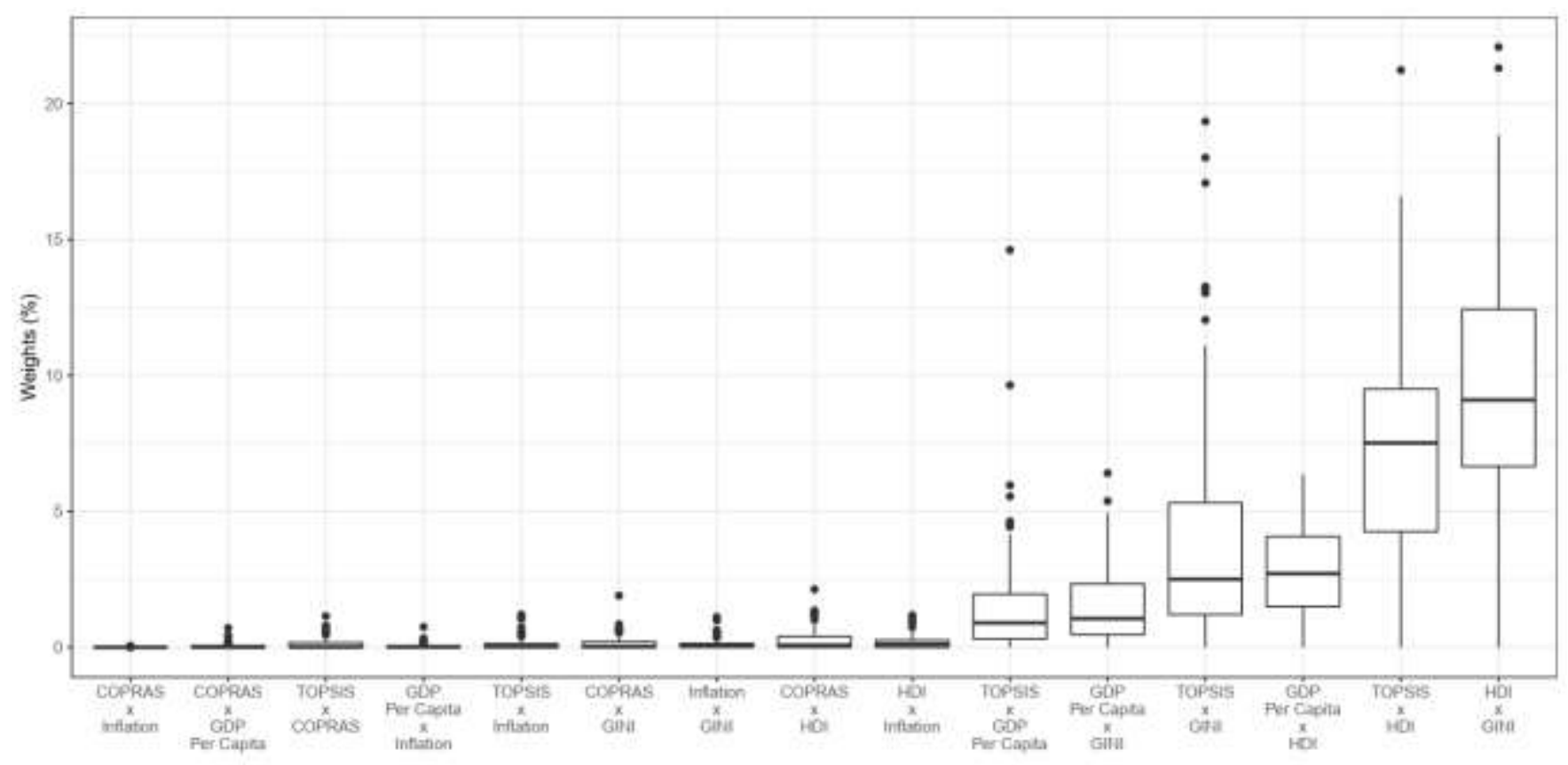

Fig. 5. Endogeneity weights for pairs of models (1)-(6). 
Percentile $97.5 \%$

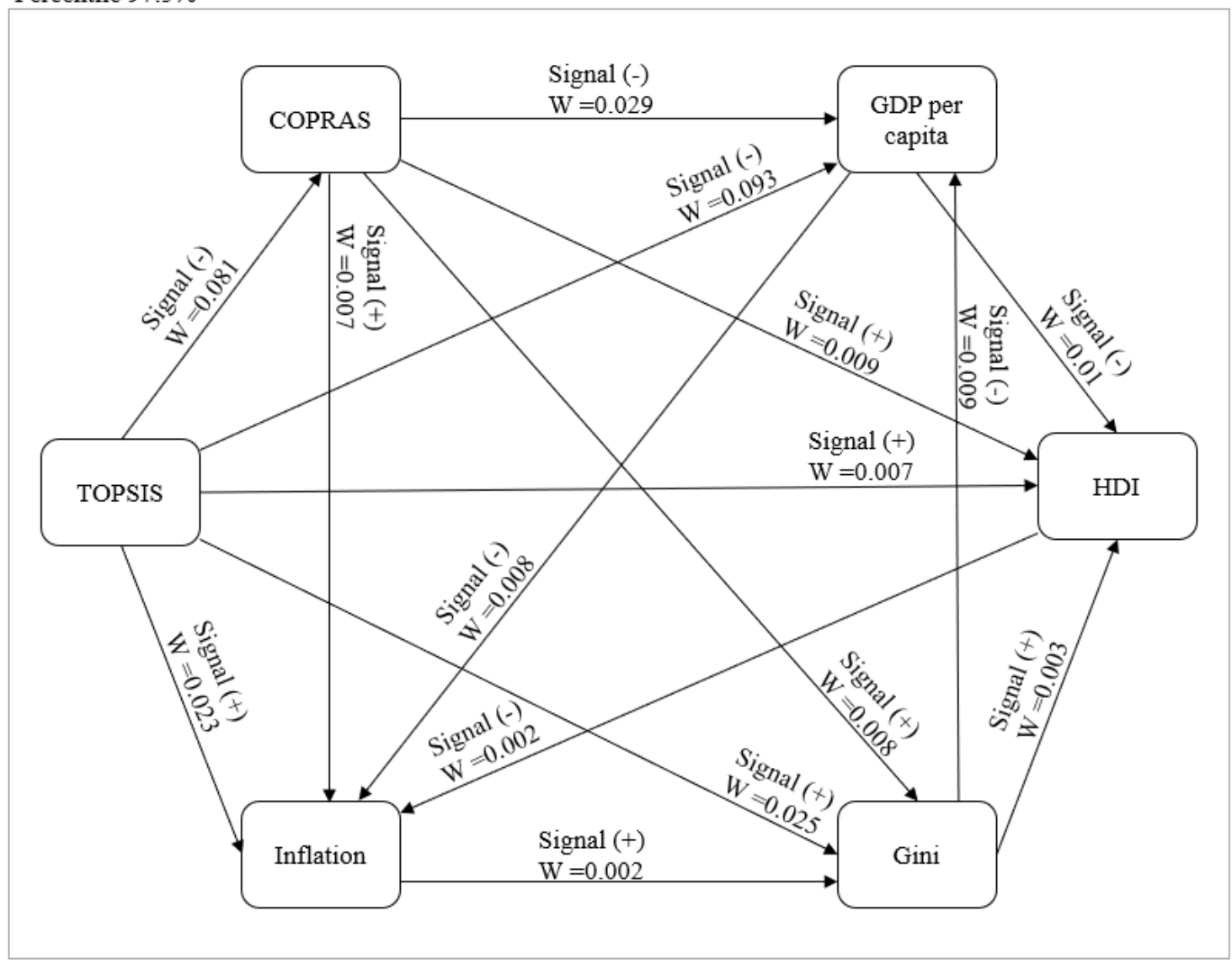

Fig. 6. Results for the structural relationship model (signs were mapped from Fig. 7). 

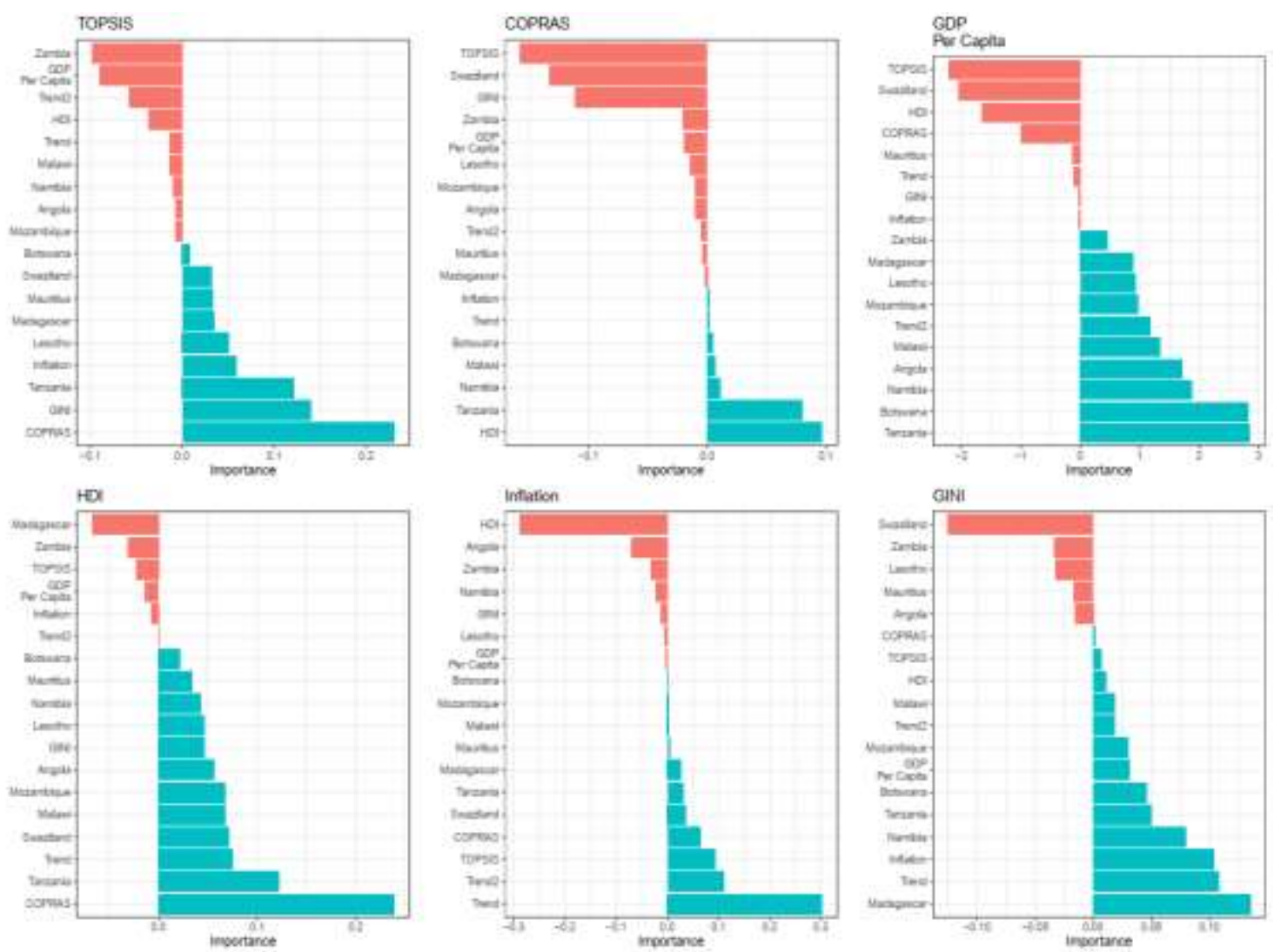

Fig. 7. Results for Olden's sensitivity analysis in terms of signs and relative importance for models (1) - (6). (South Africa as reference Country)

\section{Conclusions, limitation and policy implication}

Although this study has made several important contributions, we acknowledge a few limitations as follows. Firstly lack of consecutive data in all the periods of analysis for Zimbabwe as well as missing data for Seychelles and the DRC made it impossible to carry out a complete SADC study. It is possible that Seychelles and DRC are/were non-subscription members to the Bankscope database. Moreover, Comoros joined the SADC union in 2017, a period falling outside the time range of the current study.

In light of the results obtained for SADC of a positive association between bank performance and HDI indicators, we call on bank managers and policymakers to aspire to and 
maintain high levels of bank performance in order to augment government efforts to increase human development standards. Policymakers have an important role to preserve a healthy external socio-economic environment in which banking can thrive to influence economic development positively. Our study also uncovered that high bank performance is negatively associated with per capita GDP. Although somewhat paradoxical, Kablan (2010) reached similar findings of a negative but significant association between per capita GDP and cost efficiency for SSA banks. Perhaps this is a reflection of the high levels of concentration and income inequality that generally characterize high-income countries in this context South Africa and Mauritius. This could be the case given the negative association we also found between bank performance and the Gini index. The divergent and low levels of banking sector depth among SADC countries is worrisome as it undermines current efforts towards regional integration for Africa. In particular, underdeveloped banking sectors retard efforts towards financial integration and convergence. Thus progressing forward, issues of convergence in the African banking sector should continue to concern researchers and policymakers, particularly given current debates and ongoing discussions around a borderless Africa, intra-Africa trade and African Continental Free Trade Area (AfCFTA) agreements. Financial and macroeconomic convergence for the region, therefore, constitutes an important public policy issue that should dominate research in the future.

As discussed previously, from a policy perspective, the banking sector in the SADC countries should focus on the improvement of bank performance, this can be possibly achieved by the following ways: 1) financial innovation would be very impotant due to the fact that it is helpful to reduce the cost of production through using the financial technology, in addition, through financial innovation, more financial products can be provided to the customers, this would be helpful to increase the source of bank income, in paritular, the volume of non-interest income; 2) 
following AfCFTA agreement, it is recommended that the countries in the SADC countries should further open up the financial sector, in particular the banking sector, the resulted increase in the level of competition is supposed to provide more incentive to the bank managers to put more effort in banking operation through optimizing the resources in the daily operation derived from higher level of competition, therefore, it would further improve bank performance. This is in line with the competition-efficiency hypothesis (Tan et al., 2021).

\section{References}

Abel, S., and Le Roux, P. (2016). An Evaluation of the Nexus Between Banking Competition and Efficiency in Zimbabwe. Studies in Economics and Econometrics, 40(3), 1-20.

Adeabah, D., \& Andoh, C. (2019). Market power, efficiency and welfare performance of banks: evidence from the Ghanaian banking industry. ZBW Leibniz Information Centre for Economics, Kiel, Hamburg.

Adesina, K. S. (2019). Bank technical, allocative and cost efficiencies in Africa: The influence of intellectual capital. The North American Journal of Economics and Finance, 48, 419-433.

Adusei, M. (2016). Determinants of bank technical efficiency: evidence from rural and community banks in Ghana. Cogent Business and Management, 3(1), 1-15.

Akande, J. O. (2018). Do competition, regulation and stability matter for efficiency in sub-saharan african banking sectors? Cogent Economics and Finance, 6(1), 1493667.

Aluko, O. A., \& Ajayi, M. A. (2018). Determinants of banking sector development: Evidence from sub-saharan African countries. Borsa Istanbul Review, 18(2), 122-139.

Almeida, A. T., Almeida, J. A., Costa, A. P. C. S., \& de Almeida-Filho, A. T. (2016). A new 
method for elicitation of criteria weights in additive models: flexible and interactive tradeoff. European Journal of Operational Research, 250(1), 179-191.

Amin, S. H., Razmi, J., \& Zhang, G. (2011). Supplier selection and order allocation based on fuzzy SWOT analysis and fuzzy linear programming. Expert Systems with Applications, 38(1), $334-342$.

Apergis, N., \& Polemis, M. L. (2016). Competition and efficiency in the MENA banking region: a non-structural DEA approach. Applied Economics, 48(54), 5276-5291.

Asongu, S. A. (2012). African financial development dynamics: big time convergence. African Journal of Economic and Management Studies, 5(2), 160-194.

Banyen, K., and Biekpe, N. (2020). Financial integration, competition and bank efficiency: evidence from Africa's sub-regional markets. Economic Change and Restructing, 53, 495518.

Bara, A., Mugano, G., \& Le Roux, P. (2017). Bank concentration, country income and financial development in SADC. Southern African Business Review, 21(1), 150-176.

Barros, C. P., \& Wanke, P. (2005). An analysis of African airlines efficiency with two-stage TOPSIS and neural networks. Journal of Air Transport Management, 44-45, 90-102.

Bekar, E. T., Cakmakci, M., \& Kahraman, C. (2016). Fuzzy COPRAS method for performance measurement in total productive maintenance: a comparative analysis. Journal of Business Economics and Management, 17(5), 663-684.

Berger, A. N., \& Humphrey, D. B. (1997). The efficiency of financial institutions: International survey and directions for future research. European Journal of Operational Research 98(2), 175-212. 
Booth, P. (2011). The social role of banks is banking. https://iea.org.uk/blog/the-social-role-ofbanks-is-banking

Büyüközkan, G., Göçer, F., 2019. A Novel Approach Integrating AHP and COPRAS Under Pythagorean Fuzzy Sets for Digital Supply Chain Partner Selection. IEEE Transactions on Engineering Management, 1-18.

Chai, J., Liu, J. N. K., \& Ngai, E.W.T. (2013). Application of decision-making techniques in supplier selection: a systematic review of literature. Expert Systems with Applications, 40(10), $3872-3885$.

Chang, B., Chang, C.-W., \& Wu, C.-H. (2011). Fuzzy DEMATEL method for developing supplier selection criteria. Expert Systems with Applications, 38(3), 1850-1858.

Cooper, W.W., Seiford, L.M., and Tone, K., (2007). Data envelopment analysis: a comprehensive text with models, applications, references and DEA-Solver software (2nd ed.). Springer.

Dhiman, H.S., Deb, D., 2020. Fuzzy TOPSIS and fuzzy COPRAS based multi-criteria decision making for hybrid wind farms. Energy 202, 117755.

Diaz-Balteiro, L., González-Pachón, J., and Romero, C. (2017). Measuring systems sustainability with multi-criteria methods: A critical review. European Journal of Operational Research, 258(2), 607-616.

Elyasiani, E., \& Mehdian, S. (1990). Efficiency in the commercial banking industry: a production frontier approach. Applied Economics, 22(4), 539-551.

Feng, B., Fan, Z. P., \& Li, Y. (2011). A decision method for supplier selection in multi-service outsourcing. International Journal of Production Economics, 132(2), 240-250.

Gandhi, S., Mangla, S. K., Kumar, P., \& Kumar, D. (2016). A combined approach using AHP and 
DEMATEL for evaluating success factors in implementation of green supply chain management in Indian manufacturing industries. International Journal of Logistics Research and Applications, 19 (6), 537-561.

Gupta, H., \& Barua, M. K. (2017). Supplier selection among SMEs on the basis of their green innovation ability using BWM and fuzzy TOPSIS. Journal of Cleaner Production, 152, 242258.

International Monetary Fund (n.d.). Indicators of financial structure, development and soundness. In: Financial sector assessment: A handbook. https://www.imf.org/external/pubs/ft/fsa/eng/pdf/ch02.pdf

Islam, S. M. N., and Clark, M. (2002). The relationship between economic development and social welfare: a new adjusted GDP measure of welfare, Social Indicators Research, 57, 201-229.

Kablan, S. (2010). Banking Efficiency and Financial Development in Sub-Saharan Africa. (Working Paper n 10/136). IMF.

Kassem, A., \& Jafar Hakim, L. (2016). Assessing critical success factors (CSFs) for a supplier in a relationship-driven B2B-market.[ Unpublished master's dissertation] KTH Royal Institute of Technology.

Ladime, J., and Brahmana, R. K. (2021). Role of controlling shareholders on the performance of efficient african banks. African Development Review, forthcoming.

Lagos, R., and Rocheteau, G. (2005). Inflation, output and welfare. International Economic Review, 46, 495-522.

Mardani, A., Hooker, R. E., Ozkul, S., Sun, Y., Nilanshi, M., Sabzi, H. Z., and Fei, G. C. (2019). Application of decision making and fuzzy sets theory to evaluate the healthcare and medical 
problems: A review of three decades of research with recent developments. Expert Systems with Applications, 137, 202-231.

Maredza, A., \& Ikhide, S. (2013a). Dealing with the challenge of generating employment in South Africa: does banking sector efficiency matter? International Business and Economics Research Journal, 12(11), 1361-1372.

Maredza, A., \& Ikhide, S. (2013b). Exploring the nexus between bank efficiency and access to banking services in South Africa: A panel data analysis of the big-four [Paper presentation]. 7th International Business Conference (IBC). Victoria, Australia.

Mishra, A.R., Rani, P., Pandey, K., Mardani, A., Streimikis, J., Streimikiene, D., Alrasheedi, M., (2020). Novel Multi-Criteria Intuitionistic Fuzzy SWARA-COPRAS Approach for Sustainability Evaluation of the Bioenergy Production Process. Sustainability 12(10), 4155.

Moyo, B. (2018). An analysis of competition, efficiency and soundness in the South African banking sector. (ERSA working paper 747). Economic Research Southern Africa..

Osuagwu, E. S., Isola, W. A., and Nwaogwugwu, I. C. (2018). Measuring Technical Efficiency and Productivity Change in the Nigerian Banking Sector: A Comparison of Non-parametric and Parametric Techniques. African Development Review, 30(4), 490-501.

Rajesh, R., \& Ravi, V. (2015). Supplier selection in resilient supply chains: a grey relational analysis approach. Journal of Cleaner Production, 86, 343-359.

Rezaeisaray, M., Ebrahimnejad, S., \& Khalili-Damghani, K. (2016). A novel hybrid MCDM approach for outsourcing supplier selection: A case study in pipe and fittings manufacturing. Journal of Modelling in Management, 11(2), 536-559.

Sarpong-Kumankoma E., Abor, J., \& Aboagye, A. Q. Q. (2017). Freedom, competition and bank 
efficiency in Sub Saharan Africa. International Journal of Law and Management, 59(6) 13591380.

Sharma, P., Gounder, N., \& Xiang, D. (2013). Foreign banks, profits, market power and efficiency in PICs: Some evidence from Fiji. Applied Financial Economics, 23(22), 1733-1744.

Shaw, K., Shankar, R., Yadav, S. S., \& Thakur, L. S. (2012). Supplier selection using fuzzy AHP and fuzzy multi-objective linear programming for developing low carbon supply chain. Expert Systems with Applications, 39(9), 8182-8192.

Siraj, I., Stephan, A., and Mutarindwa, S. (2021). Ownership and bank efficiency in Africa: ture fixed effects stochastic frontier analysis. Journal of Financial Stability, forthcoming.

Stanujkic, D., Karabasevic, D., \& Zavadskas, E. K. (2015). A framework for the selection of a packaging design based on the SWARA method. Inzinerine Ekonomika-Engineering Economics, 26(2), 181-187.

Stewart, T. J., \& Durbach, I. (2016). Dealing with uncertainties in MCDA. In S. Greco, M. Ehrgott, \& J. R.Figueira (Eds.), Multiple criteria decision analysis (pp. 467-496). Springer.

Tan, Y., Wanke, P., Antunes, J., and Emrouznejad, A. (2021). Unveiling endogeneity between competition and efficiency in Chinese banks: a two-stage network DEA and regression analysis. Annals of Operations Research, https://doi.org/10.1007/s10479-021-04104-1

Triki, T., Kouki, I., Dhaou, M. B., and Galice, P. (2017). Bank regulation and efficiency: What works for Africa? Research in International Business and Finance, 39, 183-205.

Valipour, A., Yahaya, N., Md Noor, N., Antuchevičienė, J., \& Tamošaitienė, J. (2017). Hybrid SWARA-COPRAS method for risk assessment in deep foundation excavation project: An Iranian case study. Journal of Civil Engineering and Management, 23(4), 524-532. 
Van den Bergh, J. C. J. M., and Botzen, W. J. W. (2018). Global impact of a climate treaty if the human development index replaces GDP as a welfare proxy. Climate Policy, 18, 76-85.

Wanke, P., Barros, C.P., \& Emrouznejad, A., (2016). Assessing productive efficiency of banks using integrated Fuzzy-DEA and bootstrapping: A case of Mozambican banks. European Journal of Operational Research, 249(1), 378 - 389.

Wanke, P., Maredza, A., \& Gupta, R. (2017). Merger and acquisitions in South African Banking: A network DEA model. Research in International Business and Finance, 41, 362-376.

Wanke, P., Barros, C. P., and Emrouznejad, A. (2018). A comparison between stochastic DEA and fuzzy DEA approaches: revisiting efficiency in Angolan banks. Rairo Operations Research, 52(1), 285-303.

Wanke, P., Azad, M. A. K., Emrouznejad, A., \& Antunes, J. (2019). A dynamic network DEA model for accounting and financial indicators: A case of efficiency in MENA banking. International Review of Economics and Finance, 61, 52-68.

Wodon, Q., and Yitzhaki, S. (2002). Evaluating the impact of government programs on social welfare: The role of targeting and the allocation rules among program beneficiaries. Public Finance Review, 30, 102-123.

Zavadskas, E. K., \& Kaklauskas, A. (1996). Determination of an Efficient Contractor by Using the new Method of Multi Criteria Assessment”. In Langford, D. A.; Retik, A. (eds.) International Symposium for "The Organization and Management of Construction". Shaping Theory and Practice. Vol. 2: Managing the Construction Project and Managing Risk. CIB W 65; London, Weinheim, New York, Tokyo, Melbourne, Madras. - London: E and FN SPON, 94-104. 
Zolfani, S. H., Yazdani, M., and Zavadskas, E. K. (2018). An extended stepwise weight assessment ratio analysis (SWARA) method for improving criteria prioritization process. Soft Computing, 22, 7399-7405.

\section{Appendices}

Appendix 1. Optimal neural network architecture for models (1) - (6)

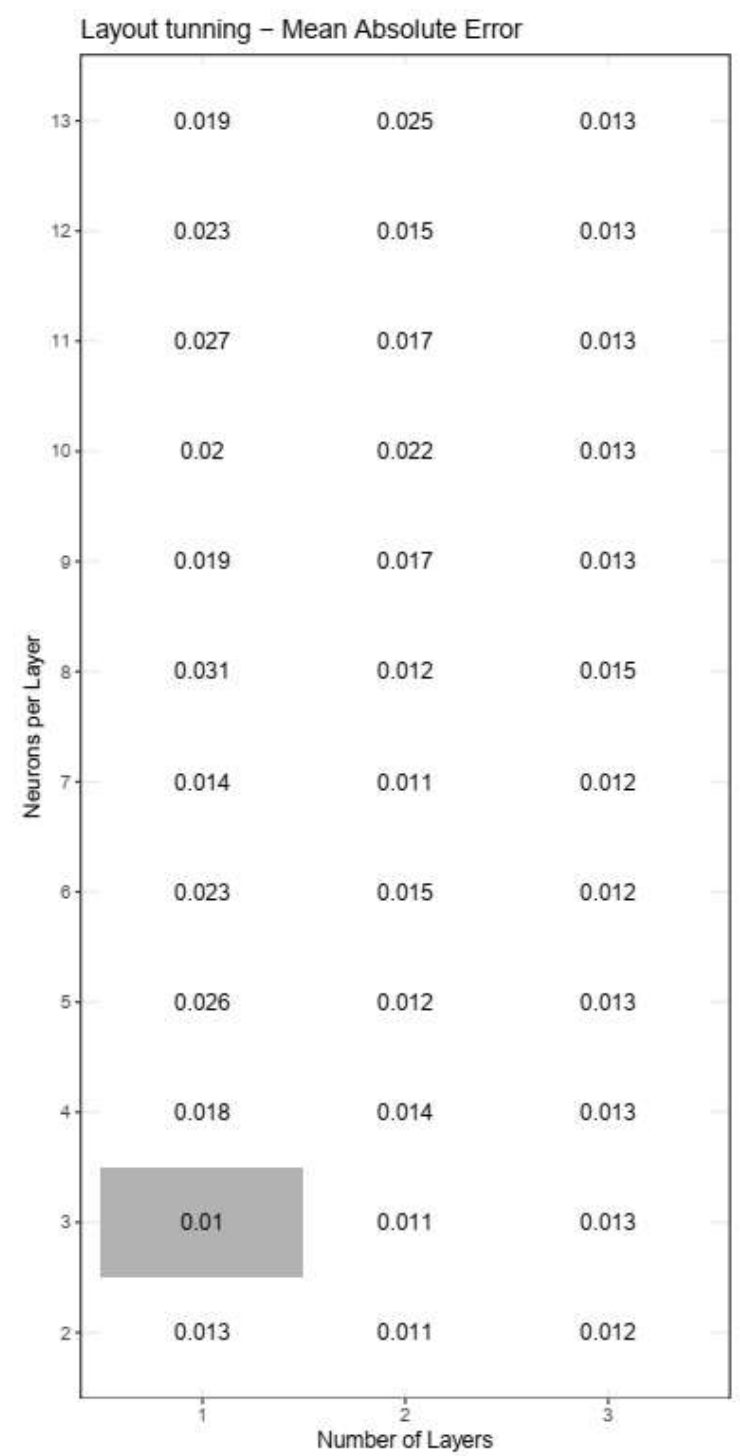

Fig. A1. Mean Squared Error layout tunning results. 
